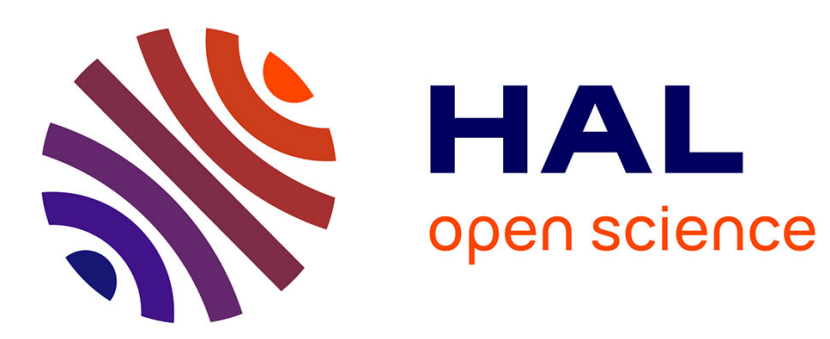

\title{
Analysis on Snow Distribution on Sunlight Greenhouse and Its Distribution Coefficient
}

Chunhui Dai, Xiugen Jiang, Min Ding, Dongxin Lv, Guilin Jia, Peng Zhang

\section{To cite this version:}

Chunhui Dai, Xiugen Jiang, Min Ding, Dongxin Lv, Guilin Jia, et al.. Analysis on Snow Distribution on Sunlight Greenhouse and Its Distribution Coefficient. 8th International Conference on Computer and Computing Technologies in Agriculture (CCTA), Sep 2014, Beijing, China. pp.575-588, 10.1007/978-3-319-19620-6_64 . hal-01420274

\section{HAL Id: hal-01420274 \\ https://hal.inria.fr/hal-01420274}

Submitted on 20 Dec 2016

HAL is a multi-disciplinary open access archive for the deposit and dissemination of scientific research documents, whether they are published or not. The documents may come from teaching and research institutions in France or abroad, or from public or private research centers.
L'archive ouverte pluridisciplinaire HAL, est destinée au dépôt et à la diffusion de documents scientifiques de niveau recherche, publiés ou non, émanant des établissements d'enseignement et de recherche français ou étrangers, des laboratoires publics ou privés. 


\title{
Analysis on Snow Distribution on Sunlight Greenhouse and Its Distribution Coefficient
}

\author{
Chunhui Dai ${ }^{1, \mathrm{a}}$, Xiugen Jiang ${ }^{1, \mathrm{~b}},{ }^{*}$ Min Ding ${ }^{1, \mathrm{c}}$,Dongxin Lv ${ }^{1, \mathrm{~d}}$, Guilin Jia ${ }^{1, \mathrm{e}}$, Peng \\ Zhang 2 , \\ ${ }^{1}$ College of Water Resources \& Civil Engineering, China Agricultural University, Beijing \\ 100083, China; \\ ${ }^{2}$ China Aerospace Construction Group Co., Ltd, Beijing 100071, China; \\ adaichunhui@cau.edu.cn, biangxiugen@tsinghua.org.cn, ${ }^{\mathrm{c}}$ dingmin@cau.edu.cn \\ d1056026017@qq.com, ${ }^{\mathrm{e}} 1251613521 @$ qq.com, ${ }^{\mathrm{d}}$ zhangpengcau@ @ohu.com
}

\begin{abstract}
There is no corresponding snow distribution coefficient for snow distribution on widely used sunlight greenhouse in the current Greenhouse structure design load code (GB/T 18622-2002). To present snow distribution and its distribution coefficient on sunlight greenhouse, the collapse reason of sunlight greenhouse under snow load in recent years was discussed by investigation and analysis. Failure modes of sunlight greenhouse under extreme snowstorm were achieved. According to the current greenhouse structure design load code in our country, 7 snow distribution types of sunlight greenhouse were put forward and its distribution rules were analyzed; Take basic snow pressure in the Beijing for example, the mechanical behavior of sunlight greenhouse under 7 snow distribution types were analyzed by using the finite element analysis software ANSYS considering the greenhouse skeleton initial defect. The calculation model of snow distribution coefficient for sunlight greenhouse was proposed. The fruits are useful to the perfection of snow load calculation method for sunlight greenhouse.
\end{abstract}

Keywords: sunlight greenhouse, snow load, distribution rule, snow distribution coefficient

\section{Introduction}

Because of little material, low construction cost, strong adaptability to the climate and plant efficiency is relatively high, sunlight greenhouse skeleton has been widely used in our country in recent years. Greenhouse in addition to providing basic space of animal and plant growth and production and the suitable temperature and humidity environment, also need to undertake include abnormal operating condition and various loads produced by extreme natural disasters (blizzard, wind, hail) [1-3].

From the perspective of the structure, sunlight greenhouse is a typical light structure, its load-bearing skeleton is generally consists of prefabricated steel pipe or steel welded together. Design load is the basic foundation of structure design, also is the primary factor for structure reliability and economy. Snow load is one of the main live load for sunlight greenhouse, its definition, value calculation directly affect the safety and economy of the greenhouse structure. In our country, building structures in the specification for industrial and civil buildings have been made the snow load 
definition and calculation values clear. But now, the industrial and civil building code and relevant standards abroad are still used for the greenhouse structure snow load calculation. There is a big difference in the degree of safety, importance, roofing and other aspects of snow distribution coefficient, what is worse, it lack of unity and pertinence.

Now the greenhouse has been widely research by scholars at home and abroad. Liang Zongmin[4]、Gong Wanting[5] 、Morcous G[6]、Castellano S[7-8] et al studied the wind and snow load in the greenhouse structure design and its effect on the bearing capacity of greenhouse. Zhang zhaoqiang[9] pointed out that, base on the contrast analysis of loads provided in foreign and China standards, under the present conditions, It is feasible in calculation snow load when considering the importance factor, the exposure factor and the heating factor according to China architectural structure load standards (GB50009 - 2001). Through the study of Wang Dongxia[10], probabilistic distribution model of wind and snow load in arbitrary design reference period is established by adopting Bernoulli trials, calculation of characteristic value of wind and snow load is put forward on the basis of "mode method". Yu YongHua[11] apply nonlinear finite element and the method of artificial stiffness, establish a calculation model of greenhouse film load effect analysis, and combined with the relevant specification, get the greenhouse film load calculation formula and the value of safety factor.

Snow distribution rule is one of the important factors affecting the snow distribution coefficient, and influence on the mechanical performance of the greenhouse structure. The greenhouse structure design load standard of GB/T 186222002 [12] (hereinafter referred to as the "Chinese standard") only provisions snow load distribution coefficient for the slope roof, single span arch roof, double slope multi span roof and multi span arch roof, But the snow distribution coefficient for the solar greenhouse, which is widely used in China, is not given. The distribution of the current standard stipulated by the snow load distribution coefficient can't fully meet the needs of its structural design in our country.

This paper study the collapse reason of sunlight greenhouse under snow load in recent years in China; According to the current greenhouse structure design load code of GB 50009-2012 [13] in our country, put forward its snow distribution rules; The mechanical behavior of sunlight greenhouse under different snow distribution types were analyzed by using the finite element analysis software ANSYS.

\section{The Collapse of Sunlight Greenhouse under Snow Load}

\subsection{Disaster Instances}

In north China, frequent extreme weather to a snow disaster, every year the heavy snow caused collapse accidents occur frequently, which brought huge losses to agricultural production. Through Xinhua network to collecting the collapse of sunlight greenhouse under snow load in recent years in China, analysis is as follows:

(1) On November 1, 2009, the town of LiXian, Daxing district, Beijing, were affected by the cold air, the snow lasting since more than $2 \mathrm{o}$ 'clock in the morning to 
the afternoon $16 \mathrm{o}$ 'clock, snow thickness was up to $12 \mathrm{~cm}$, which caused great damage on the agricultural production development in LiXian. After detailed statistics, from the department of agriculture, Liyi, Hebei and Hebeitou, etc, total 42 village of greenhouses suffered from snow storms. Including $1216 \mathrm{mu}$ of greenhouse facilities, 40 greenhouse structures collapsed. As shown in Fig. 1 (a) and (b).

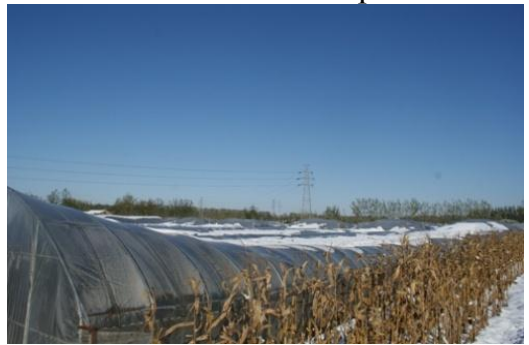

(a) Store in the front of the roof

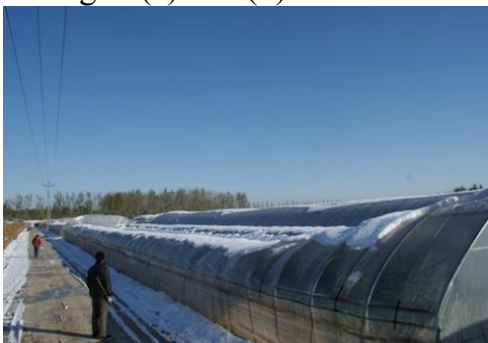

(b) Store in the front of the roof

Fig.1. Da'xing, Beijing

(2) On November 10 to 12, 2009, big blizzard has fallen in He'nan province, a lot of anti-season vegetables were damaged by the collapse of sunlight greenhouse under snow load in Hua county. As shown in Fig. 2 (a) and (b).

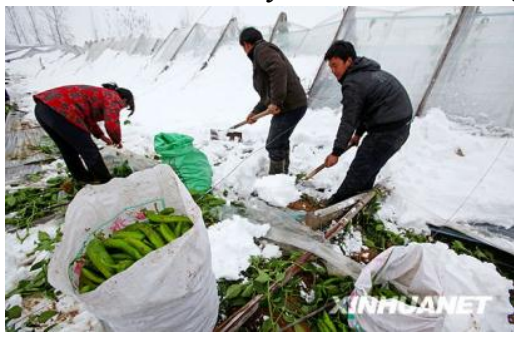

(a) Snow piecewise uniform distribution

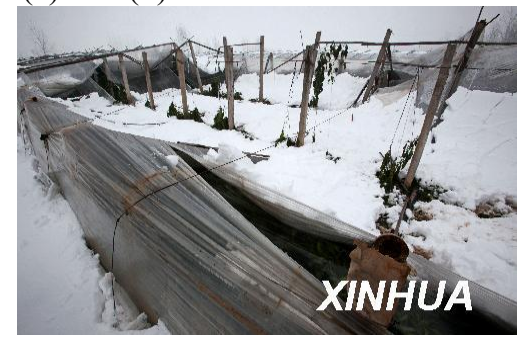

(b) Snow piecewise uniform distribution

Fig.2. Hua county,He'nan province

(3) On November 11, 2009, A severe blizzard struck the Dali county, Shanxi province, which seriously caused great losses to the local agriculture. The number of villages and towns, whose agricultural facilities had been affected, was up to 16 . The affected area was $16675 \mathrm{mu}$, of which there are 473 sunlight greenhouses collapsed, $95 \%$ of greenhouses overwhelmed by heavy snow, $70 \%$ of bamboo poles were broken by snow pressure, $50 \%$ of the film was damaged, more than $1000 \mathrm{mu}$ of cucumber seedling suffered from cold, more than $10000 \mathrm{mu}$ of autumn capsicums were total crop failure, direct economic loss was up to 54.52 million yuan. As shown in Fig. 3 (a) and (b). 


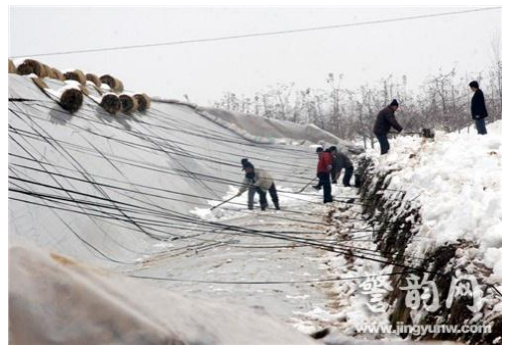

(a) Snow concentrated at the bottom

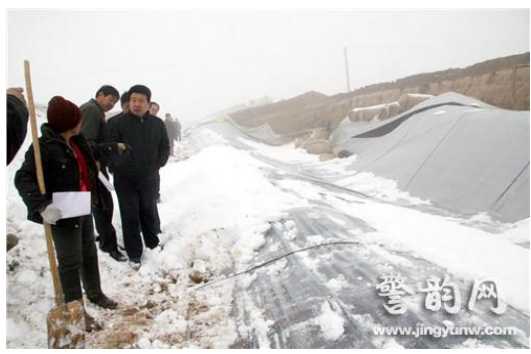

(b) Snow concentrated on the top

Fig.3. Dali, Shanxi province

(4) From February 28, 2010, 16 o 'clock to March 1, 3 o 'clock, Shouguang, a city of Shandong province, was suffered the biggest snowfall in 20 years, rainfall was up to $25.6 \mathrm{~mm}$, The thickness of the snow on the ground was more than $20 \mathrm{~cm}$. About $30 \%$ of the sunlight greenhouse deformation was very large, $5 \%$ of them collapsed, which seriously caused great losses to the local agriculture. As shown in Fig. 4 (a) and (b).

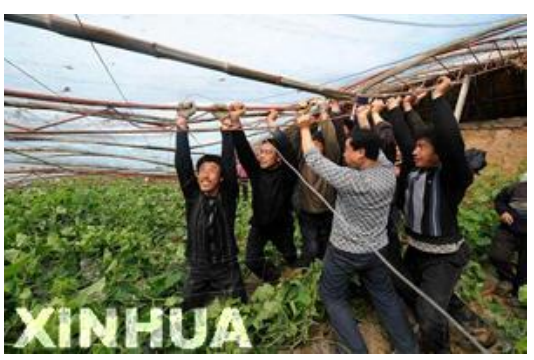

(a) Snow concentrated on the top

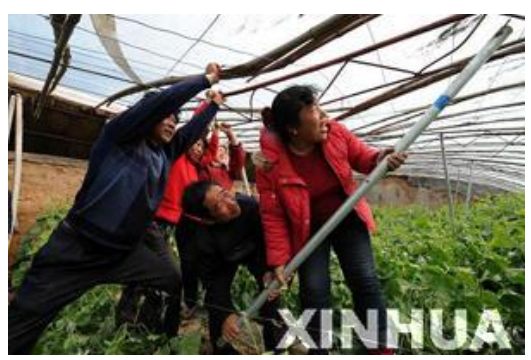

(b) Snow concentrated on the top

Fig.4. Shouguang, Shandong province

(5) The influence of snow disaster on greenhouse in Gansu province in March 2010. As shown in Fig. 5 (a) and (b).

On March 5 to 8 , a sustained strong cooling blizzard attacked Jiayuguan city, rainfall was up to $9.8 \mathrm{~mm}$, from March 620 o 'clock to March 720 o 'clock, when rainfall was $6.3 \mathrm{~mm}$. It can be a blizzard.

On March 7, Qingquan town of Yumen city suffered once every 50 years of blizzard. Thereby it cause loss to the local crops and greenhouse, such as the direct economic loss was up to 1.3748 million yuan. According to the statistics, 49 sunlight greenhouses were crushed and $121 \mathrm{mu}$ of onion seedling suffered from cold until March 10 in Qingquan town.
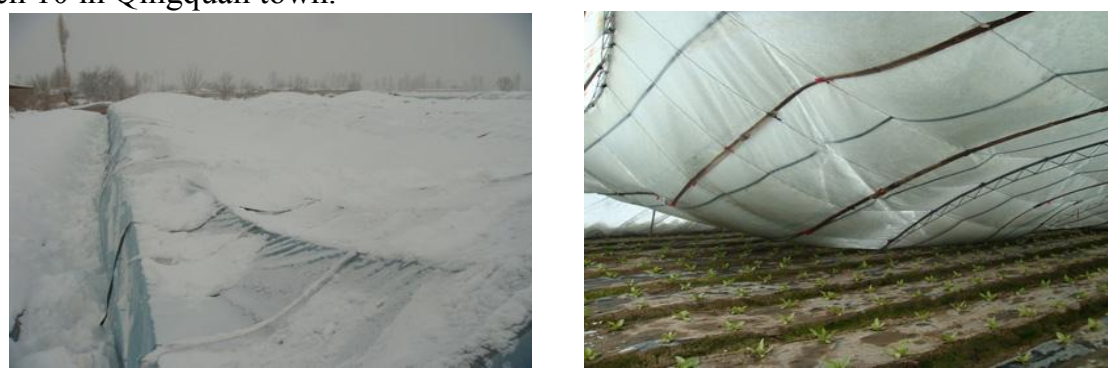
$\begin{array}{ll}\text { (a) Snow piecewise uniform distribution } & \text { (b) Snow concentrated on the top }\end{array}$

Fig.5. Yumen, Gansu province

(6) On March 10 to 11, 2010, March 13, 14, after a heavy snowfall in Hailun city, Heilongjiang province, local area can reach blizzard degree, part of the crops were affected, especially Helen town, Lunhe town, Gonghe town and Haibei town. A lot of tent poles were broken, a great many seedling suffered from cold. According to statistics, The number of sheds and greenhouses was more than 170, the affected area was 5.2 hectares, 1 hectare was total crop failure, direct economic loss was up to 2.55 million yuan. As shown in Fig. 6 (a) and (b).

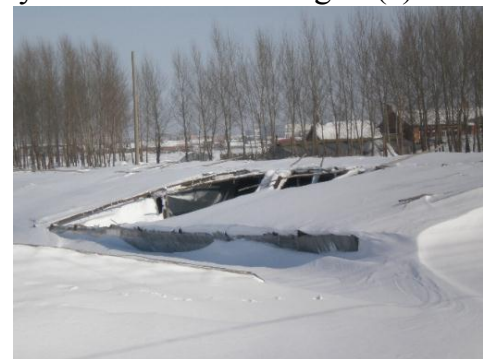

(a) Snow uniform distribution

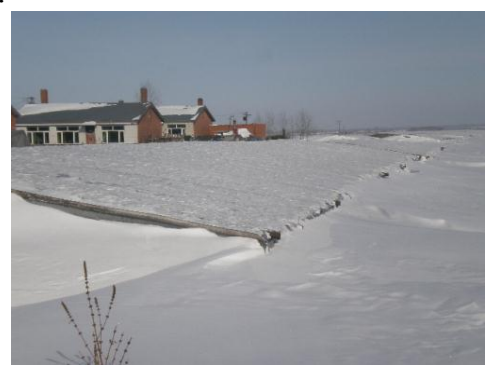

(b) Snow uniform distribution

Fig.6. Hailun, Heilongjiang province

(7) On 18-20 January, 2011, after three days of consecutive heavy snow, a lot of greenhouse vegetables were under different degree of loss in Wanzai county, Yichun city, Jiangxi province. According to preliminary statistics, more than 1500 greenhouses were affected, including more than 1100 bamboo greenhouses and more than 400 steel greenhouses, the direct economic loss was up to more than 3 million yuan. As shown in Fig. 7.

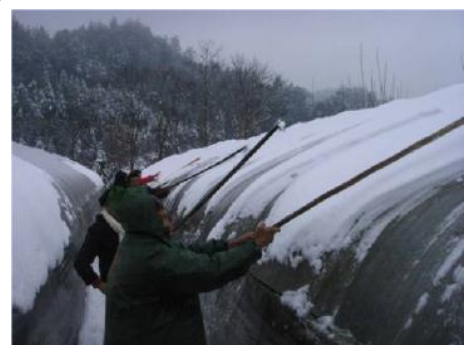

Fig.7. Wanzai, Jiangxi province

\subsection{Collapse Reason and Analysis}

Through collecting a large number of sunlight greenhouse under snow load in recent years, at the same time analysis the pictures listed above, you can get the following information:

(1)The snow distributions on the roof were not evenly distributed, it can be influenced by wind speed and temperature, snow on front of the roof may produce a concentrated load, then, generate adverse impact on greenhouse structure. 
(2)The less damage was caused by covered film strength, more for roof snow when sunlight greenhouse under the snow. Greenhouse skeleton instability caused the collapse of the whole structure, the insufficient of skeleton strength lead to fracture, then, the whole structure was destroyed.

(3) The back of the greenhouse roof width is narrower, and cant for right angle; thin film surface is smooth and easy to slide, so snow is not easy to be destroyed. In the pictures above, the back of the greenhouse roof is not damaged.

\section{Snow Distribution Rule of Sunlight Greenhouse}

\subsection{Snow Distribution Type}

The collapse reason of sunlight greenhouse under snow load in recent years was discussed by investigation and analysis. According to the current greenhouse structure design load code in our country, 7 snow distribution types of sunlight greenhouse were put forward and its distribution rules were analyzed. As shown in Fig. 8.

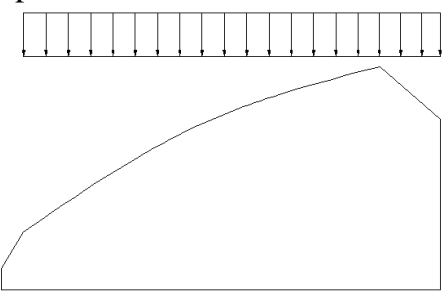

(a) Distribution form 1

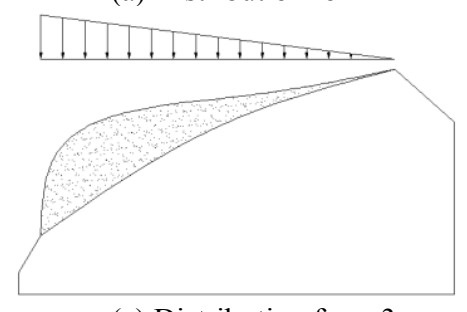

(c) Distribution form 3

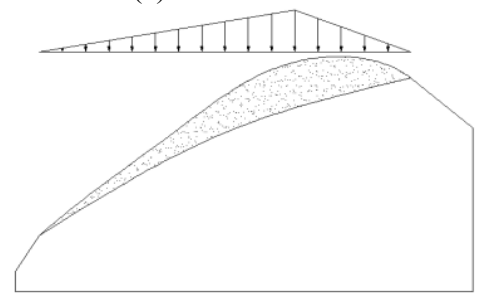

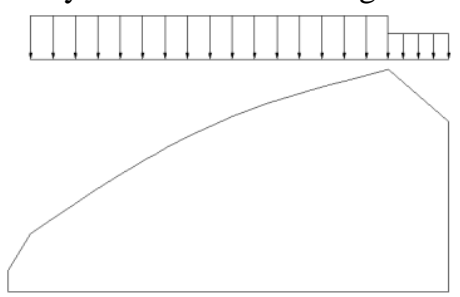

(b) Distribution form 2

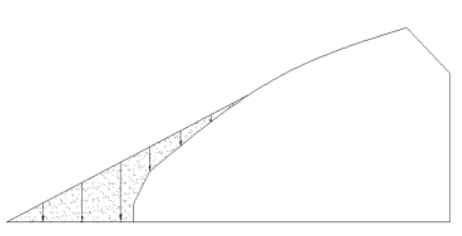

(d) Distribution form 4

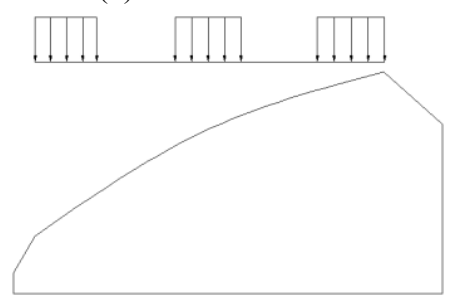




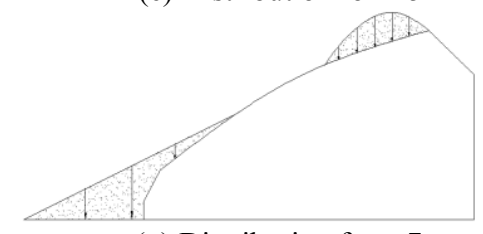

(g) Distribution form 7

Fig.8. Snow distribution type

\subsection{Snow Distribution Rule}

(1) Distribution form 1: snow was uniform distribution, because the roof slope was slow, what was more, the front and back of roof slope were similar, and there was no wind or wind was small when snowed. Fig. 6 (a) and (b) both belong to this situation.

(2) Distribution form 2: snow was uniform distribution, just because the front and back of roof slope were large different, so the thickness of snow. The back of the roof slope was steep, so snow was easy to slide down, snow thickness is very small. The front of the roof slope was slow, so snow thickness is very big. Fig. 7 belongs to this situation.

(3) Distribution form 3: the snow thickness was biggest in the middle parts of the roof, backwards gradually reduced. The reason was that the indoor temperature of greenhouse was higher. So snow melted down and slid down, finally stored in the front of the roof; otherwise, some deformation was due to the front without pillar, greenhouse structure was weak and skeleton was instability, local sag, snow is piling up. Fig. 1 (a) and (b) belong to this situation.

(4) Distribution form 4: Most of snow slid down, concentrated at the bottom of the slope before greenhouse. Fig. 3 (a) belongs to this situation.

(5) Distribution form 5: the snow thickness was biggest in the middle parts of the roof, forwards and backwards gradually reduced. The reason is that the front of the roof was the windward side, so snow moved back in under the action of wind, finally snow stored in relatively flat parts, and made local pressure very big. Fig. 4 (a) and (b) and Fig. 5 (b) all belong to this situation.

(6) Distribution form 6: snow was piecewise uniform distribution. The reason is that the horizontal skeleton and vertical purlins were linked together and strong, or the film stiffness and tension was insufficient. So the film sagged under snow load, and formed a separated phenomenon. Fig. 2 (a) and (b) and Fig. 5 (a) all belong to this situation.

(7) Distribution form 7: Most of snow slid down, concentrated at the bottom of the slope before greenhouse. But the roof close to the top was flat, so snow did not slide down. The concentrated force on both ends of the roof finally formed. Fig. 3 (b) belongs to this kind of situation. 


\section{Collapse of Sunlight Greenhouse under Snow Load}

In order to study the mechanical behavior of sunlight greenhouse under snow load, considering the universality and according to the commonly used specifications of sunlight greenhouse, make 7 different snow distribution types for the parameter. Analyzed by using the finite element analysis software ANSYS considering 2\% [11] as the initial defect on the model.

\subsection{Size of the Model}

Light steel structure was used in sunlight greenhouse structure whose skeleton was square steel pipe. The section size is $0.05 \mathrm{~m} * 0.05 \mathrm{~m} * 0.003 \mathrm{~m}$, the distance between two adjacent greenhouse skeleton was $1 \mathrm{~m}$.

The function of greenhouse arch curve:

$$
\begin{cases}y_{0}(x)=-0.9958 x^{3}+2.1918 x & x \in[0,0.6] \\ y_{1}(x)=2.7775 x^{3}-6.792 x^{2}+6.2671 x-0.8151 & x \in[0.6,0.803] \\ y_{2}(x)=0.00602 x^{3}-0.1156 x^{2}+0.9062 x+0.6189 & x \in[0.803,6.4] \\ y_{3}(x)=0.761 x+8.011 & x \in[6.4,8.0]\end{cases}
$$

Sunlight greenhouse model is as shown in Fig. 9.

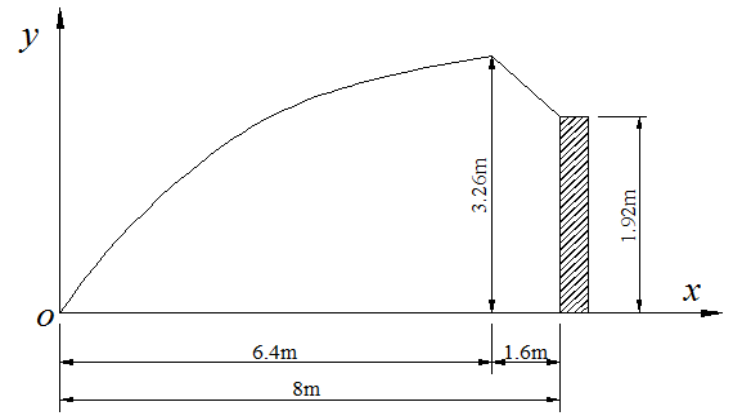

Fig.9. Sunlight greenhouse model

\subsection{Material Performance}

Chinese Q235 steel was used in sunlight greenhouse skeleton, material parameters were shown in Table 1.

Table1. Parameters of material

\begin{tabular}{ccccc}
\hline Category & Density $/ \mathrm{kg} \cdot \mathrm{m}^{-3}$ & $\begin{array}{c}\text { Elasticity } \\
\text { modulus } / \mathrm{GPa}\end{array}$ & Poisson ratiol & $\begin{array}{c}\text { Yield } \\
\text { strength /MPa }\end{array}$ \\
\hline Skeleton & 7850 & 206 & 0.3 & 235 \\
\hline
\end{tabular}




\subsection{Unit and Meshing}

The mechanical behavior of sunlight greenhouse under 7 snow distribution types were analyzed by using the finite element analysis software ANSYS. Choose Beam188 unit, Structure was divided into 40 nodes. Number them from 1 to 40 . It would be divided into a single unit when between two adjacent nodes. Structure was divided into 40 units.

\subsection{Load and Constraints}

The research content was one single skeleton in this paper. Snow load was surface load. Firstly, transform the surface load into line load; secondly, the mechanical behavior of sunlight greenhouse skeleton was analyzed with curved beam line load decomposition method [15]. The ends of the greenhouse skeleton were fixed. In this paper, we mainly considered the mechanical behavior of sunlight greenhouse skeleton with different snow distribution forms

For snow distribution form 1, take the same snow distribution coefficient for the front and back slope, According to the construction load standard GB 50009-2012 [13] (hereinafter referred to as the "specification") regulations, take the arched roof uniform distribution coefficient values as snow distribution coefficient.

For snow distribution form 2, according to the specification, take the arched roof uniform distribution coefficient values as front slope snow distribution coefficient, and the back slope was half of the front slope.

For snow distribution form 3, the front slope of snow was not evenly distributed. According to the specification, take the maximal arched roof snow uneven distribution coefficient as maximum value. The snow distribution coefficient of the back slope was 0 .

For snow distribution form 4, considering the snow slide to the bottom, part of the snow scattered on ground, take snow distribution coefficient approximate to 1 .

For snow distribution form 5, the maximal snow distribution coefficient of the front slope was the same as the snow distribution form 3, but the snow load was triangular distribution on the front slope.

For snow distribution form 6 , according to the specification, take the arched roof uniform distribution coefficient values as front slope snow distribution coefficient, the whole structure was divided into three range, loaded in turn.

For snow distribution form 7, considering the snow slide to the bottom, take snow distribution coefficient of the front slope approximate to 1; part of snow was on the roof, take the arched roof uniform distribution coefficient values as snow distribution coefficient.

\subsection{Calculation Model}

According to the specification, the start loading position was on that the angle between tangent of the curve and the horizontal was $60^{\circ}$. The calculation model was as shown in Table 2. 
Table 2. Parameters of every computation model

\begin{tabular}{cccccc}
\hline Category & $\begin{array}{c}\text { Snow } \\
\text { distribution } \\
\text { form }\end{array}$ & $\begin{array}{c}\text { Start } \\
\text { loading } \\
\text { position } \\
\alpha /^{\circ}\end{array}$ & $\begin{array}{c}\text { snow } \\
\text { distribution } \\
\text { coefficient } \\
\mu_{I}\end{array}$ & $\begin{array}{c}\text { snow } \\
\text { distribution } \\
\text { coefficient } \\
\mu_{2}\end{array}$ & $\begin{array}{c}\text { The length of } \\
\text { the load } \\
/ \mathrm{m}\end{array}$ \\
\hline Standard condition & 1 & 60 & 0.49 & 0.49 & 7.76 \\
\hline Loading angle condition 1 & 1 & 50 & 0.49 & 0.49 & 7.52 \\
Loading angle condition 2 & 1 & 65 & 0.49 & 0.49 & 7.92 \\
\hline Snow distribution condition 1 & 2 & 60 & 0.49 & $0.49 / 2$ & 7.76 \\
Snow distribution condition 2 & 3 & 60 & 2.0 & 0 & 6.0 \\
Snow distribution condition 3 & 4 & - & 1.0 & 0 & 2.4 \\
Snow distribution condition 4 & 5 & 60 & 2.0 & 0 & 6.0 \\
Snow distribution condition 5 & 6 & - & 1.0 & 0 & $1.2 \times 3$ \\
Snow distribution condition 6 & 7 & - & $1.0(0.49)$ & 0 & $2.4+1.2$ \\
\hline
\end{tabular}

Annotation: (1)Loading angle conditions 1 and loading angle conditions 2 considering the snow loading angle distribution form 1 changing in standard condition.

(2) The basic snow pressure of the Beijing was $0.4 \mathrm{kN} / \mathrm{m}^{2}$ [13].

\subsection{The results and analysis}

According to the load model, calculate the results by using ANSYS finite element software. For example, in standard condition, the start loading position was on that the angle between tangent of the curve and the horizontal was $60^{\circ}$, in other words, load from number 4 node, The length of the load was $7.76 \mathrm{~m}$. Results of mechanical analysis were shown in Fig. 10.
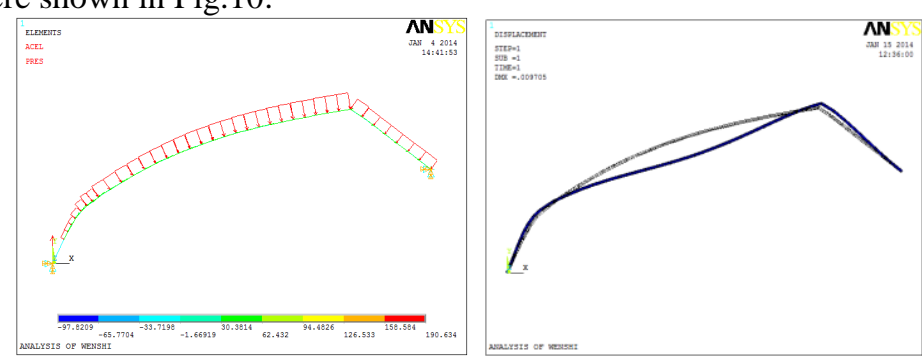

(a) The model of loading

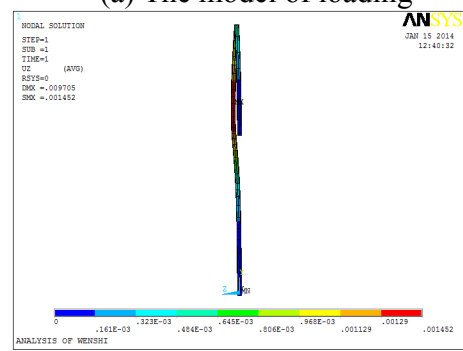

(b) The deformation of skeleton

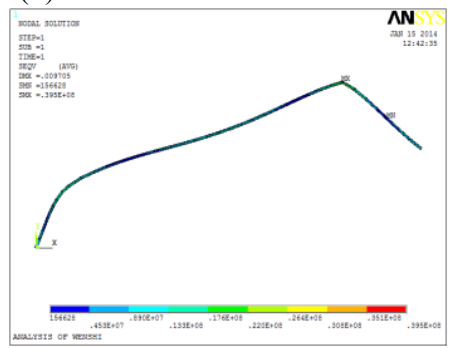


(c) The out-of-plane displacement of skeleton (d) Stress of skeleton

Fig.10. Results of mechanical analysis

As the stress nephogram and deformation pattern above shown, the maximum stress was $39.5 \mathrm{MPa}$, the position was on the outer edge of the skeleton near vault point (position: near node 33); the maximum displacement of whole structure was 9.7 mm (position: near node 22), the maximum out-of-plane displacement of whole structure (UZ) was $1.5 \mathrm{~mm}$ (position: near node 22).

Summary of sunlight greenhouse mechanical analysis is shown in Table 3.

Table 3. Summary of sunlight greenhouse mechanical analysis

\begin{tabular}{cccccccc}
\hline \multirow{2}{*}{ Category } & \multicolumn{3}{c}{ Maximum stress } & \multicolumn{2}{c}{ Maximum displacement } & \multicolumn{2}{c}{$\begin{array}{c}\text { maximum out-of-plane } \\
\text { displacement }\end{array}$} \\
\cline { 2 - 7 } & $\sigma_{\max } / \mathrm{MPa}$ & Position & $d_{\max } / \mathrm{mm}$ & Position & $U Z_{\max } / \mathrm{mm}$ & Position \\
\hline Standard condition & 39.5 & Vault point & 9.7 & No. 22 node & 1.5 & No. 22 node \\
\hline Loading angle condition 1 & 39.4 & Vault point & 9.7 & No. 22 node & 1.5 & No. 22 node \\
Loading angle condition 2 & 39.5 & Vault point & 9.7 & No. 22 node & 1.5 & No. 22 node \\
\hline Snow distribution condition 1 & 41.6 & Vault point & 10.3 & No. 21 node & 1.4 & No. 22 node \\
Snow distribution condition 2 & 74.4 & Vault point & 21.9 & No. 19 node & 1.9 & No. 22 node \\
Snow distribution condition 3 & 30.9 & The end of & 10.3 & No. 16 node & 0.7 & No. 22 node \\
Snow distribution condition 4 & 114 & Vack slope & & & & \\
Snow distribution condition 5 & 24.2 & Vault point & 5.8 & No. 21 node & 0.9 & No. 22 node \\
Snow distribution condition 6 & 28.2 & Vault point & 8.3 & No. 17 node & 0.9 & No. 22 node \\
\hline
\end{tabular}

From Table 3, we can get the following:

(1) When sunlight greenhouse was under snow load, the position of the maximum stress often appeared in vault point of sunlight greenhouse skeleton or the end of skeleton; the position of maximum displacement and maximum out-of-plane displacement often appeared in the middle of the skeleton.

(2) It had no effect on the mechanical performance of the greenhouse skeleton when start loading angle slightly changed around $60^{\circ}$.

(3) When snow was uniformly distributed on the sunlight greenhouse, and the back slope snow coefficient was half of the front slope snow coefficient, (The back of the roof slope was steep, so snow was easy to slide down, and snow thickness is very small. The front of the roof slope was slow, so snow thickness is very big.), the maximum stress and the maximum displacement were larger than when the snow coefficient was same.

(4) When snow was not evenly distributed on the sunlight greenhouse, and the distribution form was form 3 (The reason was that the indoor temperature of greenhouse was higher. So snow melted down and slid down, finally stored in the front of the roof.) or form 5 (The front of the roof was the windward side, so snow moved back in under the action of wind, finally snow stored in relatively flat parts.), the maximum stress and displacement of sunlight greenhouse skeleton were larger than others; If the snow distribution form was form 5, the maximum stress and displacement of greenhouse structure were the biggest of all. 
(5) When sunlight greenhouse was under snow load, snow was uniformly distributed on the roof or not, so this paper suggested that the snow distribution coefficient can be calculated as shown in Fig.11.

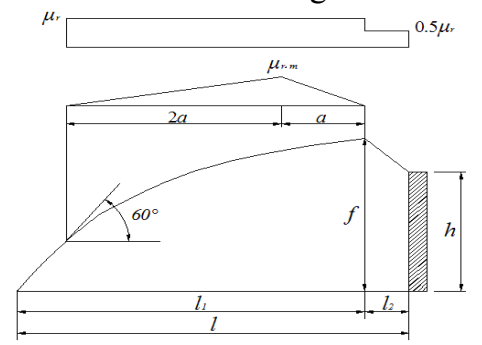

$$
\mu_{r}=\frac{l_{1}}{4 f}\left(0.4 \leq \mu_{r} \leq 1.0\right), \mu_{r, m}=0.2+5 \frac{f}{l_{1}} \quad\left(\mu_{r, m} \leq 2.0\right)
$$

Fig.11. Proposed calculation model of snow distribution coefficient for sunlight greenhouse

\section{Conclusions}

To study the mechanical behavior of sunlight greenhouse under snow load, the method of investigation and numerical simulation were used, and the different snow distribution forms of sunlight greenhouse, which were made the snow as variables, were summarized. The analysis results reflected effect on the mechanical behavior of sunlight greenhouse when sunlight greenhouse was under different snow distribution forms.

(1) When sunlight greenhouse was under snow load, the position of the maximum stress often appeared in vault point of sunlight greenhouse skeleton or the end of skeleton; the position of maximum displacement and maximum out-of-plane displacement often appeared in the middle of the skeleton. So strengthen two ends of the greenhouse skeleton and vault point were necessary, as well as in making effective vertical and lateral support in the middle of skeleton.

(2) When sunlight greenhouse was under snow load, the snow distribution coefficient can be calculated as shown in Fig.11.

\section{Acknowledgment}

Support for this research by Beijing Natural Science Foundation No. 3144029, Chinese Universities Scientific Fund No. 2011JS126, and the Specialized Research Fund for the Doctoral Program of Higher Education of China No. 20110008120017. 


\section{References}

1. Zhou Changji. Modern greenhouse project [M].Beijing: Chemical Industry Press, 2003:1-2(in Chinese)

2. Zhou Changji. The development of China's modern greenhouse and standardization [J].Transactions of the Chinese Society of Agricultural Engineering, 2003,19 (Supplement) : 88-91.

3. Zhou Changji. The enlightenment of the greenhouse collapse caused by snowstorm [J].Agricultural Engineering Technology, 2007, (12) : 13-15.

4. Liang Zongmin. Design theory on wind-resistance reliability of structure for multi-span greenhouse [D]. Beijing: China Agricultural University, 2004. (in Chinese with English abstract)

5. Gong Wanting, Liang Zongmin. Numerical simulation of wind pressure on the surface of the new greenhouse [C]. Beijing modality of the 17th academic essays, Beijing, 2011:7374.

6. Morcous G. Performance of conservatories under wind and snow loads[J]. Journal of Architectural Engineering, 2009, 15(3): 102-109.

7. Castellano S., Candura A., Scarascia-Mugnozza G..Greenhouse Structures S1S Analysis: Experimental Results And Normative Aspects[C]. International Conference on Sustainable Greenhouse Systems - Greensys, 2004.

8. Castellano S., Mugnozza G.S., Vox G. Collapse Test on a Pitched Roof Greenhouse Structure[J]. Colture Protette, 2006, 35(1): 55-61.

9. Zhang Zhaoqiang. A preliminary study on calculating of snow load for greenhouse structural design [J]. Construction Technology of Low Temperature, 2003, (3): 36-37.

10. Wang dongxia. Study of nominal value of wind and snow load of the greenhouse structures with unified warranty probability[C]. Academic essays of the second session of the national civil engineering graduate student academic BBS, Shanghai, 2004.

11. Yu Yonghua, Wang jianping, Ying Yibin. Nonlinear finite element analysis of the bearing capacity of arch structure in plastic greenhouse on snow load working condition [J]. Transactions of the Chinese Society of Agricultural Engineering, 2007, 23 (3): 158-162.

12. General Administration of Quality Supervision, Inspection and Quarantine of the People`s Republic of China, GB/T18622-2002. The greenhouse structure design load [S]. Beijing: China Building Industry Press, 2002.

13. General Administration of Quality Supervision, Inspection and Quarantine of the People's Republic of China, GB50009-2012. Load code for the design of building structures [S]. Beijing: China Building Industry Press, 2002.

14. Wang Xinmin. ANSYS numerical analysis of engineering structures[M].Beijing: China Communications Press, 2007:353-356(in Chinese). 